\title{
Emergence of Agile Methods: Perceptions from Software Practitioners in Malaysia
}

\author{
Ani Liza Asnawi, Andrew M. Gravell and Gary B. Wills \\ School of Electronics and Computer Science, \\ University of Southampton \\ SO17 1BJ, United Kingdom \\ \{ala08r, amg, gbw\}@ecs.soton.ac.uk
}

\begin{abstract}
Agile methods are an established process for developing software nowadays. There is, however, less evidence on their usage among software practitioners in Malaysia. While the methods have become mainstream in other regions, that is not the case in this country. This paper empirically investigates the perceptions of Agile methods usage from seven organisations involving 14 software practitioners in Malaysia. Our participants are using Scrum and have a maximum of five years experience. We categorised our findings in terms of awareness, introduction, and challenges they are facing, together with the suggested and practiced solution from them. Interestingly, a change in mind set when practicing Agile was identified to be helpful in reducing the challenges. Lastly we present the practices in Agile they perceived to deliver the most benefits. We found that the use of Agile is still emerging in the country, and awareness is still lacking especially within the government sector. Although several challenges have been encountered when introducing Agile in their organisations, the benefits of Agile are reported to be in Agile practices such as: the involvement from all parties from the beginning, daily stand-up meeting, iterative and incremental, applying burn down chart, sprint and continuous integration. We aim to provide awareness and knowledge about Agile methods to the practitioners in the country and the nearby region. This paper can serve as a reference to the early adopters who intend to use Agile methods in the future.
\end{abstract}

Keywords-software process; Agile methods; perceptions; awareness; introduction; challenges; benefits; practices

\section{INTRODUCTION}

Agile methods provide ways to develop software which place emphasis on people and their creativity [1]. Despite the benefits that Agile can deliver, little work has been published regarding its current usage in the Southeast Asia region particularly in Malaysia [2]. If the methods are to be used, we need to understand how Agile methods are being practiced within this region. How is the practice perceived by the practitioners in Malaysia? What challenges and benefits have they experienced when using the methodologies? How they overcome those challenges? Agile methods are not for everyone. In one of the sessions for an invited talk at the XP2011 Conference, titled 'When Agile is not enough'; the speaker stated: "what works in one culture, will not necessarily work in other cultures"1. We agree with this statement and intend to investigate the scenario in the country. Several studies stated that addressing cultural differences is important for the success of software development [3, 4]. One study [3] which involved Malaysian software practitioners, asked the question "What has culture got to do with software development?". Although the paper discussed global software development, we believe that some Malaysian cultural aspects discussed in the paper can be related to the usage of Agile methods. Based on the findings in [3] we believe the cultural differences and problems from Malaysian practitioners will influence how Agile methods perceived and adopted in Malaysia. Malaysia is a country having a mixed population with three different ethnicities; Malay, Chinese and Indians. The national language is Malay and the second language is English. English is used widely as medium for interactions in business activities.

In this research we will investigate the perception of software practitioners in Malaysia when adopting Agile methods. Agile methods are established methodology that is believed to produce faster results when developing software. Nonetheless, Agile is not a silver bullet replacing traditional methods of software engineering, such as the Waterfall model. However, to get the best out of Agile, it must be adapted to the people and organisation of the adopters. While Agile became mainstream in the development of software in the Western countries (such as Europe, Australia and Northen America), it is not the case in other regions: Southeast Asia region [2] and countries such as Malaysia. For them, Agile is new and some have never heard of the method [5].

The lack of studies about Agile methods in the Southeast Asia region prompted us to choose Malaysia as the case under investigation. Furthermore, with the importance of software industries to the country, it is necessary to provide baseline on how to use software processes that can be adapted to frequent change in the business environment.

This paper will present the perception from practitioners in Malaysia (with different sets of interviews) after a year we conducted a baseline study in [5]. Out of 14 participants, ten new participants were recruited in this study and with the other four from the baseline study. The past participants (a project manager from company A, a

${ }^{1}$ http://xp2011.org/ (last accessed June 2011) 
project manager from $C(\mathrm{I})$, a project manager from $\mathrm{D}$, and a developer from company E) are important to provide their update on Agile adoption. In this paper, their awareness will be considered. Challenges associated with the introduction of Agile methods will be presented, together with solutions suggested by the practitioners (see section $\mathrm{V}$, part $\mathrm{D}$ ). The practices perceived to deliver the most benefits are also presented. As qualitative study is always concerned with validity and reliability of the findings, these issues are discussed before we conclude the paper.

\section{BACKGROUND AND MOTIVATION}

Although there are some papers about the perception from adopters of Agile methods, however, these studies were mainly carried out in Western countries such as Canada, the European region and the United States [6-8]. We need to understand the perceptions of practitioners particularly from other region.

\section{A. Research Questions}

In this paper, several questions will be addressed:

- What do practitioners say about awareness of Agile in the country?

- What are the first reason(s) making they started to use Agile methods?

- What are the challenges they faced when using Agile?

- Despite the challenges, what are Agile Practices perceived to deliver the greatest benefits to them?

\section{B. Objectives and Expected Contribution}

We will describe the perceptions of practitioners in the country in terms of awareness, Agile introduction, challenges they are facing, and the benefits they obtained when using the methods. The challenges of using Agile methods can serve as guidelines for software practitioners in Malaysia and the nearby region where only limited studies about this field exist. It is hoped that the findings will help to reduce the difficulties encountered when they are trying to introduce Agile methodologies. In addition, this study will help add to the empirical evidence of software engineering knowledge and software processes in terms of Agile methods usage. We hope that based on our findings from this study, the usage of the methods will increase and at the same time, add to the awareness of the Agile methodologies in the country.

As many new participants compared to the initial study [5], therefore, this paper will provide and add more qualitative evidence to the study in terms of Agile adoption and its introduction in the country specifically in terms of Agile perception .

\section{THE IMPORTANCE OF SOFTWARE INDUSTRIES AND SOFTWARE PROCESS IN MALAYSIA}

The software industry has had a major impact on the economic growth in Malaysia. Since 1990, Malaysia's economic growth has been outstanding with a double GDP per capita achieved [9]. Realising the important contribution of the software industry to the economic growth and how it can help the community, Malaysia has started focusing on it. This is important in order to transform the country into a developed and technological country [10]. Receiving full support from the government, the Multimedia Super Corridor (MSC) is an effort to support the information communication technology (ICT) sectors in the country. In addition, it is the vision of MSC to make Malaysia as a global hub and preferred locations for ICT and multimedia innovations, services and operations [11]. Consequently, looking at the importance of the industry to the growth of the economy and the community as a whole, ICT has become one of the focuses of the $10^{\text {th }}$ Malaysia plan $(2011-2015)^{2}$. So, the industry should continue to expand over this period.

In order to have smooth operation of software development and successful deployment of the industry in ICT, the needs of software processes are considered to be critical. The problems found from one study [12] show that Malaysia is still lacking the usage of software processes. Besides, the problems in terms of delivering quality products have also been identified [12]. In addition, recent investigation has discovered that companies in Malaysia do not have a clear methodology that illustrates how the requirements can be obtained [13]. The need for a good software process is important as it can help practitioners define their requirements. These problems have motivated us to introduce Agile methods in the country. As Agile emphasis on collaboration with customers and having works iteratively and incrementally, it will help to reduce some of the associated problems [12, 13]. We expect the problems can be minimised with the application of the methods. To the best of our knowledge and based on a review of literature, we found very little information and published studies about Agile methods used in Malaysia.

\section{THE STUDY}

This study is part of our research into investigating the adoption of Agile methods in Malaysia. This paper focus on reporting what practices from Agile methods they use, the awareness, how they first introduced to Agile, challenges they are facing and the benefits they received from the Agile methods.

\section{A. Methodology}

In this study, we conducted a qualitative semi structured interview to understand the perception of new adopters in Malaysia. As software development deals with human

2 www.bernama.com/bernama/v5/newsbusiness.php?id=504844 (last accessed 18 June 2010) 
factors, a qualitative study therefore helps in understanding the respondents' behaviour, and to identify the unknown and never explored scenarios [15]. Unlike the quantitative approach, a qualitative study will help to describe what is actually happening when one programme (in our case Agile methods) was implemented [16].

\section{B. Study Design}

Questions in this interview were developed from the findings obtained in the baseline study [5]. The issues identified in the baseline study have been the basic references and consequently created hypotheses investigating the perception of software practitioners when using Agile methods. This is a semi-structure interview and therefore the questions are adapted to the answers given by the participants. There are three sections for the interview questions; (i) introduction, (ii) factors of adoption, and (iii) demographic. As stated above, the issues from the baseline study were used to generate hypotheses in terms of (i) technology, (ii) involvement, (iii) people, (iv) organisation, (v) knowledge and the (vi) relative importance of the factors. This paper only identifies the perceptions from the practitioners. Due to limited space we have, the questions cannot be attached with this paper. However, they can be obtained by emailing the first authors.

\section{Participants}

They were 14 interview subjects in total with four of them also the participants from the baseline study [3]. According to Kvale, this number of respondents is appropriate for this kind of study [17]. Marczyk et al suggested having six to ten subjects for interview [18] and shared; by adding more subjects, the research will diverge and become difficult for the researcher to draw strong conclusions.

Since this is a qualitative study, therefore the participants are purposely chosen rather than at random [19]. The suggestion behind the qualitative study is to purposefully select participants or sites [15]. The participants chosen are based on the following criteria; (i) software practitioners including developers, testers, system analyst, business analyst and project managers involved in Agile project, and (ii) with experience of at least currently using Agile methods. Taking benefits from their positions is consistent with the objective of the study. The benefit of this purposive sampling is to allow the researcher understanding the scenario from the right participants.

\section{Data Collection}

The data were collected from seven software organisations in Malaysia, between February and March 2011, involving 14 software practitioners. The purpose and implications of the research were explained to the participants before we started the interviews. At the same time, we sought prior consent from the participants by providing forms to be signed. Our study has been granted an ethical approval under the School of Electronic and Computer Science, University of Southampton. The interviews were recorded using a voice recorder. Hand written notes were also taken while the interviews were recorded. This is important for reference and can be compared with our recorded data later on in the analysis stages.

\section{E. Data Analysis}

The data were transcribed and they were compared with the notes we took during the interview. We ensured only the relevant data were transcribed. Then the data were imported to a qualitative tool; NVivo version 8. NVivo is a tool where we can organise our qualitative data and that aided the process of data coding ${ }^{3}$. The analysis was performed using thematic analysis. Thematic analysis is a way of seeing themes and pattern from the information collected [20]. Codes are produced from themes. There are three main stages in thematic analysis which are (i) deciding on sampling and design issues, (ii) developing themes and codes, (iii) validating and using the code.

1) Deciding on Sampling and Design Issue: The data are collected from samples based on the purpose of the research. For this study, we seek to identify the perception relating to the adoption of Agile methods in Malaysia.

2) Developing Themes and Codes: In this study, a data driven approach is chosen for the thematic analysis. It is also called an inductive way of seeing data, in which the analysis is conducted from bottom to top.This approach is also called 'what data are saying' [20]. There are several steps involved; which are (i) reducing the raw information, (ii) identifying themes within subsamples, (iii) comparing themes across subsamples, (iv) creating code and lastly (v) determing the readability of the code.

3) Validating and Using the Code: The final stage in thematic analysis is to apply the code to the data again. In this process, it can be said that this is a process of looking and checking the codes with the data. The advantages for this procedure helps the study to avoid mistakes and findings are reliable. This stage was performed by the researcher and a second coder.

\section{COMPANIES OVERVIEW}

From the seven organisations that we interviewed in this study, three are multinational companies and four are local companies. All the companies in this study are using Agile methods, having a maximum of five years experience. The companies we interviewed agreed that Agile methods are still at the early stages in Malaysia where the need for its introduction is paramount. Table I provides a synopsis of the companies. The information in Table 1 was obtained from the interviewees' responses.

${ }^{3}$ http://onlineqda.hud.ac.uk/Step by step software/NVivo/index .php (last accessed 15June 2011) 
TABLE I. COMPANIES' OVERVIEW

\begin{tabular}{|c|c|c|c|c|}
\hline Company & Types & Status & $\begin{array}{l}\text { Duration } \\
\text { Using } \\
\text { Agile }\end{array}$ & $\begin{array}{l}\text { Main } \\
\text { Activity }\end{array}$ \\
\hline A & $\begin{array}{l}\text { Local (small } \\
\text { and startup) }\end{array}$ & $\begin{array}{l}\text { Fully } \\
\text { Scrum }\end{array}$ & 4 years & $\begin{array}{l}\text { Rapid web } \\
\text { application }\end{array}$ \\
\hline B & Local & $\begin{array}{l}\text { Only } \\
\text { parts of } \\
\text { Agile }\end{array}$ & $\begin{array}{l}2 \text { years } \\
\text { (started } \\
2009)\end{array}$ & $\begin{array}{l}\text { e- } \\
\text { commerce }\end{array}$ \\
\hline $\mathrm{C}(\mathrm{I})$ & Multinational & $\begin{array}{l}\text { Fully } \\
\text { Scrum }\end{array}$ & $\begin{array}{l}\text { Since June } \\
2010\end{array}$ & $\begin{array}{l}\text { Technology } \\
\text { and } \\
\text { services }\end{array}$ \\
\hline $\mathrm{C}(\mathrm{II})$ & Multinational & $\begin{array}{l}\text { Fully } \\
\text { Scrum }\end{array}$ & 4-5 years & $\begin{array}{l}\text { Technology } \\
\text { and } \\
\text { services }\end{array}$ \\
\hline $\mathrm{D}$ & Local & $\begin{array}{l}\text { Fully } \\
\text { Scrum }\end{array}$ & 2 years & $\begin{array}{l}\text { Airport } \\
\text { product, } \\
\text { critical } \\
\text { system, } \\
\text { r\&d, } \\
\text { middleware }\end{array}$ \\
\hline $\mathrm{E}$ & Multinational & $\begin{array}{l}\text { Fully } \\
\text { Scrum }\end{array}$ & 1year & $\begin{array}{l}\text { Technology } \\
\text { and } \\
\text { Services }\end{array}$ \\
\hline $\mathrm{F}$ & Multinational & $\begin{array}{l}\text { Fully } \\
\text { Scrum }\end{array}$ & 1 year & $\begin{array}{l}\text { Technology } \\
\text { and } \\
\text { Services }\end{array}$ \\
\hline G & Local & $\begin{array}{l}\text { Fully } \\
\text { Scrum }\end{array}$ & $\begin{array}{l}\text { Since end } \\
\text { of } 2010\end{array}$ & R \& D \\
\hline
\end{tabular}

\section{A. Description and Introduction of the Companies}

Company A is a small, local, start-up which believes that Agile methods are best suited to their software development. As an Agile proponent, they believe in the methods as their way to develop software. To use Agile, the founders discussed the methods with their team members and at the same time education about Agile were taught. Table II provides a summary about each participant.

TABLE II. PARTICIPANTS' SUMMARY

\begin{tabular}{|l|l|l|}
\hline Company & $\begin{array}{l}\text { Number of } \\
\text { Participants }\end{array}$ & Role(s) \\
\hline A & 1 & Founder+PM+Scrum Master \\
\hline B & 1 & System Analyst \\
\hline C(I) & 3 & Developer (2), Business Analyst \\
\hline C(II) & 5 & $\begin{array}{l}\text { Scrum Master (2), Developer, PM, } \\
\text { Business Analyst }\end{array}$ \\
\hline D & 1 & PM \\
\hline E & 1 & Developer \\
\hline F & 1 & PM \\
\hline G & 1 & Tester \\
\hline
\end{tabular}

As we can see from table II, the representative from company A holds multiple roles. The practice of Agile methods was first started by learning about it from the internet and books; however, according to them, with training they started to practice the method correctly. In addition, an Agile instructor was also called in to train the team members. Company A places emphasises on staff participation and they believe customers must also understand about the software process they are using.
Company B is only adopting parts of Agile methods and they combine prototyping with Agile methods. The reason they combine these methods is to ensure users' understanding and gain users' feedback about the system. They started using Agile methods in 2009.

C (I) and C (II) comprise one company. It is a multinational company and we interviewed practitioners from different projects and different departments; the reason for this $\mathrm{C}$ (I) and (II) were separated. The participants in C (I) were just started using Agile methods and the adoption in $\mathrm{C}$ (I) was more about following a trend where someone in the company introduced Agile. They found that the method is productive; thus the other team in the company adopted it as well. The drawbacks of Waterfall and the benefits of Agile in delivering progress are reasons they changed to Agile. The project manager in C (II) was one of our participants in the initial study [5]. They are among the first teams that adopted Agile in the organisation.

Company D is a local company and has branches in other countries. They started using the method when they heard about Agile taken place in their market. They commenced by exploring it and tried using Agile, but only began to implement Agile correctly after training. Training clarified the concept for them, following which they began to implement it seriously in their organisation.

Company $\mathrm{E}$ is a multinational company. According to the developer that we interviewed, the change in Agile methods was decided by management and they started using Agile methods in early 2010. Workshops and training on how to use Agile methods were given to them. At the time we conducted this investigation, the project was at the testing phase.

Company $\mathrm{F}$ is a multinational company which starting to use Agile methods as the other branches of its organisation had already adopted it. At that time the project manager attended Agile training in another country, as she said it was difficult to find any training in Malaysia. The training on Scrum (one of the Agile methods) in Malaysia was only introduced towards the end of 2009. According to the project manager, Agile methods suit any type of project, and there are no restrictions, however this does depend on how practitioners use it.

Company $\mathrm{G}$ is a large, local company in the country. They only started using Agile methods at the end of 2010 with piloting their projects. At the beginning they only practiced Scrum; however, for the current project, they have combined CMMI and Scrum.

The participants in this study are having range of experience of software development from one to 20 years and the maximum experience they have using Agile methods was five years. The participants interviewed are mostly from management side which cover Scrum master, the founder, project manager, and assistant vice president. In summary, they are six participants from the management side, four developers, two system analysts and both one system analyst and one tester taking part in the interviewed. The range of experiences and their roles has helped to achieve the study objective. 


\section{THE FINDINGS}

In this section, we will present our qualitative findings. The practices from Agile methods and practitioners' awareness of Agile methods will be described. Then followed with challenges and benefits they obtained from the practices.

\section{A. Agile Practice}

According to the participants we interviewed, they are using the Scrum method however company B shared they only adopting part of Scrum. Company B combines Scrum with prototyping, as according to the software analyst we interviewed, it is easier for them to obtain understanding from user. At the initial usage of Agile methods, company $\mathrm{G}$ was practicing Agile fully; however, they do combine the methods with CMMI. Other companies are using the full Scrum method. Daily stand-up meeting, user-stories, retrospective, wall stories, burn down chart, sprint planning, estimation, velocity and involvement from all parties are among the practices adopted by the companies. Although some companies claimed to be using Scrum but we identified that they have adopted other Agile practices; for example from XP.

\section{B. The Awareness of Agile Methods in Malaysia}

The awareness of Agile methods is still at the beginning stage and less exposure about the methods can be found in the country [5]. The exposure is lacking from both the customers' and practitioners' side. In our investigation, we found the awareness to be lacking from the government side, which the lacking in terms of knowledge of Agile itself. The lacking of exposure from the customers' side was also mentioned by the practitioners in this interview.

1) Beginning Stage \& Lack of Exposure: This is agreed by the companies that we have interviewed in the study. In company C (II), they said that the adoption of Agile methods in their company is still new as they had only recently adopted the methodologies from their subcompany. When asked about the awareness of Agile methods in the country, one of representatives from company C (II) mentioned; "I think in Malaysia not very long but I think it's too new in our company as well'. Most of them stated that Agile methods are still at the beginning stage in Malaysia, just taking some initial steps. Company D shared their experience when using Agile "So far, a lot of our proposals or projects implementation, the customers have not really made known of this new method. That's why there is still learning curve we need to implement in whenever we want to implement the project." Company E does not know about the awareness of Agile methods in Malaysia however, he expressed his opinion; "I am not sure how widely Agile is being used in Malaysia. I think most probably they (the practitioners) are still using the old methodologies." The representative from company $\mathrm{F}$ thinks that most of the Agile adopters in Malaysia are among those from the multinational companies; "I think however, people are taking baby steps, I think most of the companies using Agile are from multinational companies." Multinational companies may have more exposure to Agile because they received it from their sub-companies. Therefore it is perceived easier to them for adopting the methods as their other branches have already adopted Agile.

2) Lacking from Government Side:Results from our initial questionnaire showed that government contractors and employees are less aware of Agile methods than the private sector is. Furthermore, we obtained similar findings in understanding the issues from the early adopters in Malaysia [5] which was conducted a year before this study was performed. Adding to this this scenario, we found most of the participants agreed that the sector should be exposed to Agile methods. Company G suggested; "If we can go to that government agency, and map back whatever they have in Waterfall with Agile, from there they might see about Agile methods. Basically it is just the awareness." This is particularly crucial when Agile companies are dealing with projects from this sector. We quote views from our participants in this interview regarding the awareness of government sector; "Yes, they (government) are not aware. They like to STORE documentation. It is just awareness". One added: "In the government sector, yes, it takes a LOT of awareness". Company E and F did not mention about the awareness from the government side. This could be a result that they never had any projects involved with government sector.

\section{Agile Introduction}

Despite the lack of awareness about Agile is found among software practitioners in the country, however we can see that Agile methods has become the choice for some organisations that are aware of the advantages they can receive from the method. In 2009 a course called Certified Scrum Master was introduced and later in March 2011, another course was added named Certified Scrum Product Owner ${ }^{4}$. These two courses show that the need for providing information for Agile introduction is needed in the country. In this section, we will identify the reasons why, and ways in which the companies started to use Agile methods.

1) Agile Proponents and Experienced From Previous Methods: For Agile proponent, it is easy to adopt a new methodology in their organisations. Our findings show that company A started to use Agile methods because they believe in the method; "We believe in Scrum or Agile as our way to develop software." According to them, if one believes in traditional methodology, and thinks that it works for them, then they should use it as there is no right

\footnotetext{
${ }^{4}$ http://www.atsc.org.my/ (last accessed March 2011)
} 
way. However, the companies in our interview believe in Agile methods as the consequence of having bad experiences with the traditional way; as pointed out by one representative "Waterfall might work for others, but we don't want to use it, because we believe Agile works for us, we really believe Scrum as a way to go."

2) Adopting from Parent Companies: All the multinational companies in our study mentioned that they started to use Agile from their sub companies; which their teams then followed, "In a global company, we have global policy, I think we are lucky in the sense within our company, actually it's a top down direction". Another said "We are a multinational company, perhaps, because the organisation itself is supporting Agile methods." Taking this into account, we found that the introduction of Agile to the local companies is not easy. This is because they have less reference points and they need to refer to external sources for Agile guidelines.

3) Adopting the Benefits: The highest cited reason in the interviews for why the organisations concerned started using Agile methods is because the many benefits and the drawbacks of their previous software process. A developer from the multinational company $\mathrm{C}$ (I) mentioned, I believe in Agile, because Agile will be much easier when developing product. Since it feels that it is productive, so that is why we try to adopt it. It does not have to be like the Waterfall practices, where at the end, one can only see the progress and everything." The Agile methods allow the development team to see the progress of their project. The needs of having feeback from clients was one of the reasons company B started using Agile methods; "At the beginning, we need feedback from users, so that we can have better understanding." In addition to the benefits of Agile, problems with previous methodology is also the reason why they chose to use Agile; "I came from Waterfall, after that become no methodology (no methods used), as long as you deliver the project. After that the company tried to move to CMMI. I would say it just like a lot of waste in the previous method, a lot of waste, a lot of misscommunication because the communication is done at different levels, so the customers are not involved throughtout the project, there's also a long development cycle. So when we are moving to Scrum, it is more iterative and more incremental and we involve customers throughout the project until the end. So we can get frequent feedback, when you develop small and iteratively or incrementally." In addition, the organisations interviewed also agreed that using Waterfall might succeed, but it takes a long time, and there is a lot of miscommunication and unnecessary documentations.

\section{Challenges When Using the Methodologies}

Practicing a method where there is lack of adoption in the country perceived difficult, and a challenge, by the organisations we interviewed. We identified challenges in terms of (i) lack of documentation on the nature of Agile, (i) people, (ii) organisation, (iii) involvement, (iv) knowledge, (v) cultural aspects, (vi) government and (vii) resources. In our study, we did not find any challenges mentioned in terms of technical aspects when using Agile methods.

1) Lack of Documentation: The nature of Agile which does not focus on documentation is perceived a challenge to the companies in Malaysia especially to those that are still at the beginning of adopting and understanding the method. It is even more challenging to the companies that deal with government projects. According to company A, it is important for the client to know about Agile methods. When they were dealing with government projects, arguments and doubts were always coming from the government side, particularly when it comes to the documentation; "How to get paid, what's the milestone?". To solve this problem, company A agreed to flexible contracts: "In each sprint we have function, so we test it (on each function), when you are satisfied, you deploy and you pay." Company D added, "...because most of our projects we are running are government projects, they have their own policy where documents are often needed, and Scrum does not actually emphasise on comprehensive documentation, so we are looking at ways on how we can actually mature and get both parties to agree on things." From this investigation, we see that the organisation using Agile faced many questions and doubts when dealing with government projects in terms of documentation. This shows the need for a change in mind set, especially with the projects involving government sectors.

2) People: People aspects are important in Agile [1, 5] and the difficulties also lie with the people practicing the methodologies. From this study, we found that the mind set of people adopting Agile must be ready to adapt to how Agile methods work. In addition, it will be difficult to practice Agile methods when people are not willing to learn new things, as emphasised by the companies we interviewed. How Agile works is more about collaboration among the practitioners and customers, therefore people dependency was one of the challenges experienced by a business analyst from one of the multinational companies we interviewed. Company B also perceived dependency of people as a challenge. Company D uncovered differences when dealing with local people and international practitioners: "When involved with international practitioners, they know about Agile; however when dealing with a project involving 
local people, it is a bit more difficult to use Agile." The difficulties might be from the early emergence of Agile methods locally when information about the method is still lacking in the country. This is the gap we intend to reduce. Company $\mathrm{D}$ and $\mathrm{F}$ suggested that adopters need to be independent and understand their role when doing Agile. A self organising team must exist as in Agile the team that is given the power to make decision. Company A thinks that the organisation must sell the values of Agile for the people to accept and practice the methods.

3) Organisational: The challenges were also found within organisational aspects which include co-location of team members, availability of knowledge to the organisation and management support. Company F's team were distributed, but it had recently been trying to colocate them. They found difficulties when having distributed teams. According to the project manager we interviewed, a great deal of miscommunication occured especially when working with other teams in locations where there were time differences. The company considered it as waste of resources and subsequently decided to co-locate their teams. Companies C (II) and F are multinational companies that have been using Agile methods for four to five years. The representative from company F learnt Agile in the hard way; "I learnt it the hard way. Actually we had a lack of reference; even my Scrum master at that time was still new, we had no guidance, and we had to learn it ourselves." Company A has four years' experience in using Agile. The company received full support from the top management. However for company $\mathrm{G}$, the adoption of Agile methods became a challenge as the management did not understand about the methodologies: "The top management does not support too much because currently we have certain blockages from management, as our management originates from CMMI, so their mind set still cannot be changed, thus I believe the difficulties are from the organisation aspect. We managed to do Agile but without support from management, we faced a lot of pain." Practicing Agile needs support from the top management. They must understand the nature and how Agile works. Once the top management understand then the methods will go down to a low level people in the organisation and from here the whole organisation will support the usage of Agile methods (company D).

4) Involvement: The involvement in Agile methods is also perceived to be a challenge for companies B and D. Company B is only partially adopting part of Agile methods. In order to make customers collaborate or participate in their development, company B said that they need to undertake extra tasks like preparing materials to be presented to the customers. This is also considered a challenge for a system analyst in our interview (company B), who explained about his involvement in the whole process of development. Developers in company D felt that they are burdened with more tasks. Other companies believe that there is always a challenge when it comes to the involvement of customers and practitioners. Productowner role is one example that directly involves the customers. However some of the interviewees agreed that it is best when the developers have direct connection with customers. As shared by one representative of the developers, whenever they (the developers) deal with customers, they always include the project manager and product owner in any discussions.

5) Knowledge: Lack of knowledge about Agile methods also brings challenges especially when the adopters are dealing with customers. This was identified by company A when dealing with government projects (as presented above). Besides, according to company $\mathrm{F}$, the management or manager must understand the ways in which Agile works. To make Agile work, prioritisation should come from the product owner. Otherwise, if the project manager or the vice president (management side) does not understand the way Agile works, it may affect the productivity of the team, which should be avoided. The challenge in this aspect occurs in company G; "...here, we have deadlines, where the top management just give us the deadline, but then we know in Agile, you have to look into product backlog. You have to estimate and resize everything; only then we can know when we can finish. These people (management) do not understand if we say we can't meet the dateline requested." Knowledge is also perceived as a challenge when company D was recruiting new staff. They found that fresh graduates do not have knowledge about Agile methods. They know about the normal software development life cycle; this might be because they were only taught about the traditional approach during the studies. Therefore, every time fresh graduates come in to the organisation, the challenge is there to provide them with the totally new knowledge about Agile. According to company $\mathrm{D}$, having senior and junior practitioners in a team is one way to overcome this problem. In a project, when senior practitioners transfer the knowledge to junior, this way they can actually grow the team better.

6) Cultural: The cultural aspect was raised by participants from a multinational company, C (I). "I actually believe about the Malaysian thing. There is something you don't see, the culture, it's not the method. The method, yes, they will accept it, but their willingness, their behaviour, their personality, how they accept the method, the environment as well." From here, although they mentioned about the culture, the key aspects of this are people's behaviour and the organisational environment. The representative from company D also agreed on the possibility towards the difficulties of doing Agile methods from the cultural aspect. To provide Agile 
suitable for their culture, openness must be there as people value transparency and Agile is all about trust and respect. In addition, half of the respondents agreed on the language aspects when trying to understand Agile methods.

7) Resources: Lack of resources is one of the challenges adopters are facing when using Agile methods. This is also reason why some of them have multiple roles (such as combining the role of project manager and Scrum Master) when using Agile. Although having multiple roles can cause conflict of interests, the practitioners strive to make it work; "I think sometimes we are resource-hungry, for the resource of people. For instance, when we started Scrum fully, we were running a huge project, with about 10 separate modules, that's where we have 10 Scrum teams running concurrently. So it's very resource-hungry because atleast one team should have about five to six developers, so that is when we feel everything has to have their own testers, everything should have their own developers etc. They cannot be shared across each team. So at some point we actually hired a lot of people to come in for the project itself. That's why I think the resource part is quite expensive." Company A is a small, start-up company which managed to practice Agile with a practitioner holding multiple roles. According to them, it is good to have one person (provided he knows the scope and technical aspects) to act as project manager, business analyst and product owner. The company shared that, by practicing multiple roles when using Agile, decision on development can be made faster.

\section{E. The Greatest Benefit of Agile Practices}

We have identified the perception of Agile methods in terms of the introduction, awareness of them, and the challenges involved. Despite the challenges and difficulties in using Agile methods, however, the companies interviewed said that Agile practices have delivered benefits to their software development. The benefits have been identified from the practices such as wall stories, daily stand up meeting, burn down chart, involvement from all parties, iterative and incremental way, retrospective, continuous integration and user stories. The greatest benefit Agile brings are from the involvement from all parties in Agile (companies A, B, C (I), C (II), D, F and G) and daily stand up meeting (companies A, C (I), C (II), D, E and G). These two practices contribute to each other. The involvement in Agile methods has also delivered advantages to software development as practitioners can have frequent feedback from their customers. The involvement of testers at each iteration has obviously helped in delivering good quality software to them (company G).

The meeting provides a medium through which to communicate openly, which results in transparency. The practice has brought people together and it is believed to have the highest value. From here, team members understand about their roles and responsibilities. Besides giving visibility, the practice also helps to highlight any roadblocks that might occur early in the project; "We can identify problems at an early stage rather than at the end, and also we get sort of a clear picture on the stories that we need to finish by a particular period so that we can plan ahead and get them into sprint." Company D compared the daily standup meeting with their previous methodology; "I think the daily stand up has a very good impact because when we were doing Waterfall previously, we did have a sort of daily meeting, but we didn't really look at what we were going to do next, or what the issues were, because usually we just look at the project status, and what we have completed." The practice of daily stand up meeting makes more sense because they always look at three different things: (i) What are you going to do next? (ii) What you have completed? and (iii) What are the impediments?.

Company $\mathrm{F}$ believes in the practice of retrospective offered in Agile; "If you put me with the highest benefit, I would say the retrospective because we can see what we did good, so how we can improve. If we do better, how to do the best. Of course others are important to me, but the practice of retrospective is the highest." Prioritisation in Agile is also added to its benefits, mentioned by representatives from company C(II): "The good thing about Agile- we have too many changes going on, but Agile helps us to prioritise on a constant/regular basis, so that's the reason we use Agile. Agile can manage changes, it manages changes easier." The representatives said prioritisation helps them to focus. Besides, Agile gives flexibility and efficiency. Continuous integration also helps them in seeing their progress and at the same time provides transparency to their development. According to the users, the user stories techniques brings more reality to requirement; "Previously we had a user requirement book, then a requirement analysis book, these are too elaborate and UML diagram-all these do not serve our purposes. So we decided to use user stories, whereby in user stories we have acceptance criteria, and we also added scenarios, so this brings reality to requirements."

\section{DISCUSSION}

From this study we have identified the perceptions of early adopters of Agile methods in Malaysia. The awareness of Agile methods is found to be in the beginning stage and lack of exposure in the country. Agile methods are perceived as easy to learn but difficult to be put into practice. This is because the current methodologies are only providing the framework, not specific guidelines on how to practice Agile. Therefore collaboration and team working are critical in order to make Agile work. Understanding and support from the 
top management is also important for the smooth implementation of software development. Although technical aspects were not discussed in this paper, we found that there is an ongoing need for the technical aspect to aid the practice of Agile. Company A applies Ruby On Rails for their Agile software development. Most of the companies are using Microsoft Visual Studio Team Foundation Server. The less discussed technical aspects might be from the early stages of adoption where serious issues about the technical aspect may not yet have been identified. Does adopting only part of Agile methods limit the full benefits that Agile is supposed to deliver? We found companies that are fully implementing Agile methods to have positive perceptions during this study. To them, nothing is bad about Agile; however, again, it depends on how people in the team are practicing it.

This study also shows that people and knowledge are two key aspects perceived as challenges when using Agile methods. The mind set of people adopting Agile must be ready to adapt to how Agile methods work and the team must have the relevant knowledge for the Agile methods to work. In order to obtain the knowledge about Agile, people must also willing to learn new things. These two aspects (people and knowledge) can help to increase the awareness of Agile methods, thus reducing the challenges and helping with the introduction of Agile methods in the organisation. The involvement from all parties in Agile has been identified as the practices that deliver the most benefits, followed with the practice of daily stand up meeting. Table III provides a summary of the perceptions from the companies we interviewed. Table III confirms that some perceptions are widespread (with $6 / 8$ or $8 / 8$ ) organisations mentioning to concern such as lack of knowledge or achieving the benefits. Whereas others (such as lack of documentation, retrospective) are mentioned by only $1 / 8$ or $2 / 8$ companies in the interviews.

\section{VALIDITY AND RELIABILITY ISSUES}

Validity is looking for the strength of qualitative research and it is on the basis of determining the accuracy of the findings that the researcher attempts to measure [15]. This study was conducted with seven organisations and involving 14 software practitioners from both management and technical position of software organisation in Malaysia. Validity is measured based on the sampling strategy where the participants were chosen on the basis of foundation that they can conform to the objective of the study; understanding the perception of Agile methods in Malaysia. However, the participants were also ensured to have knowledge about the methods and have had experience of using Agile methods which would enable them to provide view and judgment in accordance for the objective of study. A qualitative study 'lies in a particular theme developed in context of a specific sites' hence 'particularity rather than generalisability is the hallmark of qualitative research' [15].

TABLE III. PERCEPTIONS' SUMMARY

\begin{tabular}{|c|c|c|c|}
\hline Perception & Findings & Companies & $\begin{array}{l}\text { No of } \\
\text { Companies }\end{array}$ \\
\hline \multirow[t]{2}{*}{ Awareness } & $\begin{array}{l}\text { Beginning stage } \\
\& \text { Lack of } \\
\text { Knowledge }\end{array}$ & $\begin{array}{l}\text { A, B, C (I), C } \\
\text { (II), D, F }\end{array}$ & $6 / 8$ \\
\hline & $\begin{array}{l}\text { Lacking from } \\
\text { Government } \\
\text { side }\end{array}$ & $\mathrm{A}, \mathrm{C}(\mathrm{I}), \mathrm{C}(\mathrm{II}), \mathrm{D}, \mathrm{G}$ & $6 / 8$ \\
\hline \multirow[t]{3}{*}{ Introduction } & $\begin{array}{l}\text { Agile } \\
\text { Proponent \& } \\
\text { Experienced } \\
\text { from previous } \\
\text { methods }\end{array}$ & $\begin{array}{l}\mathrm{A}, \mathrm{B}, \mathrm{C}(\mathrm{I}), \mathrm{C}(\mathrm{II}), \\
\mathrm{D}, \mathrm{G}\end{array}$ & $6 / 8$ \\
\hline & $\begin{array}{l}\text { Adopting from } \\
\text { Parents } \\
\text { Companies }\end{array}$ & $\mathrm{C}(\mathrm{I}), \mathrm{C}(\mathrm{II}), \mathrm{E}, \mathrm{F}$ & $4 / 8$ \\
\hline & $\begin{array}{l}\text { Adopting the } \\
\text { Benefits }\end{array}$ & $\begin{array}{l}\mathrm{A}, \mathrm{B}, \mathrm{C}(\mathrm{I}), \mathrm{C} \\
\text { (II), D, E, F, G }\end{array}$ & $8 / 8$ \\
\hline \multirow[t]{7}{*}{ Challenges } & $\begin{array}{l}\text { Lack of } \\
\text { documentation }\end{array}$ & A,D & $2 / 8$ \\
\hline & People & $\mathrm{A}, \mathrm{B}, \mathrm{C}(\mathrm{II}), \mathrm{D}$ & $4 / 8$ \\
\hline & Organisational & $\mathrm{F}, \mathrm{G}$ & $2 / 8$ \\
\hline & Involvement & $\mathrm{B}, \mathrm{D}$ & $2 / 8$ \\
\hline & Knowledge & $\mathrm{A}, \mathrm{F}, \mathrm{D}, \mathrm{G}$ & $4 / 8$ \\
\hline & Cultural & $\mathrm{C}(\mathrm{I}), \mathrm{D}$ & $2 / 8$ \\
\hline & Resources & $\mathrm{B}, \mathrm{C}(\mathrm{I}), \mathrm{D}$ & $3 / 8$ \\
\hline \multirow[t]{8}{*}{$\begin{array}{l}\text { Practices' } \\
\text { Benefits }\end{array}$} & $\begin{array}{l}\text { Daily stand up } \\
\text { meeting }\end{array}$ & $\begin{array}{l}\text { A,C(I),C(II), D, } \\
\text { E,G }\end{array}$ & $6 / 8$ \\
\hline & $\begin{array}{l}\text { Burn down } \\
\text { chart }\end{array}$ & $\mathrm{A}, \mathrm{C}(\mathrm{I}), \mathrm{F}$ & $3 / 8$ \\
\hline & $\begin{array}{l}\text { Involvement } \\
\text { from all }\end{array}$ & $\begin{array}{l}\text { A, B, C (I). C } \\
\text { (II), D, F, G }\end{array}$ & $7 / 8$ \\
\hline & $\begin{array}{l}\text { Iterative and } \\
\text { incremental }\end{array}$ & $\mathrm{C}(\mathrm{I}), \mathrm{D}, \mathrm{E}, \mathrm{F}$ & $4 / 8$ \\
\hline & Retrospective & $\mathrm{F}$ & $1 / 8$ \\
\hline & Sprint & $\mathrm{C}(\mathrm{I}), \mathrm{C}(\mathrm{II}), \mathrm{E}$ & $3 / 8$ \\
\hline & $\begin{array}{l}\text { Continuous } \\
\text { integration }\end{array}$ & $\mathrm{C}(\mathrm{I}), \mathrm{G}$ & $2 / 8$ \\
\hline & User stories & $\mathrm{C}(\mathrm{II}), \mathrm{G}$ & $2 / 8$ \\
\hline
\end{tabular}

Agile methods are still emerging methodologies in Malaysia which the adopters are still at minimum number. Although the study was only involving 14 software practitioners however their range of experiences in software development and in Agile methods have helped the investigation to achieve its objective. Even though we cannot assume that the findings can be representative for all software companies, however we believe that they are reasonably typical to the software development companies in Malaysia. Thus, it can be said that the participants in this study can facilitate to represents views from the Agile adopters in this country.

On the other hand, reliability means that the research approach is consistent across different projects and also different researchers [15]. In this study, the interpretations of the findings have been checked with the other researcher, making the interpretation consistent and can be trusted. Furthermore, we have checked the transcripts 
several times in order to reduce obvious mistakes during the transcription and coding procedures. Another person has cross checked the codes, thus providing the reliability for the findings obtained in this study. Double checking data can help to ensure that all the data are reflected in the findings.

\section{CONCLUSIONS}

In this paper, the perceptions have been identified from their awareness, the way they introduced the method and the challenges they are facing. The lessons learnt about perceptions are important to serve as guidelines for the adoption of Agile methods in the country. We found that a company only adopting part of Agile methods is not receiving the full benefits from the methods. This study indicates a low perception from Agile users towards the methodologies and that there is difficulty of getting everyone in the team to take responsibilities. The findings also show that people need to be confident when trying to use Agile methods. This is so as they need to see something working and proven success stories from the Agile users.

From this study, the challenges are mostly found from the organisations having hierarchical approach. Here the management is expected to set the datelines and control the process, therefore Agile is hard to be accepted (or taking time to be accepted). In addition, the junior is expected to be taught and the senior is expected to make decision. The early adoption of Agile is seen to be from the multinational companies. Although this is not unique to Malaysia, as multinational companies are receiving examples from their other branches, making it easy for the acceptance. We found that the challenges from lack of documentation, organisational aspect, involvement, knowledge and culture are all based in or related to people factor where the mind set change is needed to overcome those challenges. This study adds evidence to the knowledge of software engineering and software process; at the same time it provides knowledge and reference about Agile methods to the country and the nearby region.

\section{REFERENCES}

[1] A. Cockburn and J. Highsmith, "Agile software development: The people factor," Computer, vol. 34, pp. 131-133, Nov 2001.

[2] R. Sison, S. Jarzabek, O. S. Hock, W. Rivepiboon, and N. N. Hai, "Software practices in five ASEAN countries: an exploratory study," in Proceedings of the 28th international conference on Software engineering Shanghai, China: ACM, 2006.

[3] V. Casey, "Leveraging or Exploiting Cultural Difference?," IEEE Computer Society, 2009, pp. 8-17.

[4] M. Phongpaibul and B. Boehm, "Improving quality through software process improvement in Thailand: initial analysis." vol. 30: ACM, 2005, pp. 1-6.

[5] A. L. Asnawi, A. M. Gravell, and G. B. Wills, "Empirical Investigation on Agile Methods Usage: Issues Identified from Early Adopters in Malaysia," in Agile Processes in
Software Engineering and Extreme Programming, 2011, pp. 192-207.

[6] G. Melnik and F. Maurer, "Perceptions of agile practices: a student survey," in Extreme Programming and Agile Methods - XP/Agile Universe 2002. Second XP Universe and First Agile Universe Conference. Proceedings, Chicago, IL, USA, 2002, pp. 241-250.

[7] B. Bahli and E. S. Abou Zeid, "The role of knowledge creation in adopting extreme programming model: An empirical study," in ITI 3rd International Conference on Information and Communications Technology (ICICT 2005), Cairo, EGYPT, 2005, pp. 75-87.

[8] K. Mannaro, M. Melis, and M. Marchesi, "Empirical analysis on the satisfaction of IT employees comparing XP practices with other software development methodologies," in 5th Internationl Conference Extreme Programming and Agile Processes in Softwave Engineering, Garmisch-Partenkirchen, GERMANY, 2004, pp. 166-174.

[9] J. Gantz, L. Lee, and L. Lai, "The Economic Impact of Software and IT services on Malaysia," Kuala Lumpur, Malaysia, 2006, pp. 1-15.

[10] K. Raman and C. Yap, "From a resource rich country to an information rich society: An evaluation of information technology policies in Malaysia," Information Technology for Development, vol. 7, pp. 109-131, 1996.

[11] S. S. M. Fauzi, R. Nuraminah, and M. Nasir, The Extent of Software Process Improvement Models in Malaysia: A Focus on CMMI Models. Hong Kong: Int Assoc Engineers-Iaeng, 2009.

[12] F. Baharom, A. Deraman, and A. Hamdan, "A Survey on the Current Practices of Software Development Process in Malaysia," Journal of ICT, vol. 4, pp. 57-76, 2006.

[13] A. Zainol and S. Mansoor, "Investigation into requirements management practices in the Malaysian software industry," in 2008 International Conference on Computer Science and Software Engineering (CSSE 2008), Wuhan, China, 2008, pp. 292-295.

[14] A. L. Asnawi, A. M. Gravell, and G. B. Wills, "An Empirical Study: Understanding Factors and Barriers for Implementing Agile Methods in Malaysia," in 5th International Doctoral Symposium on Empirical Software Engineering Bolzano-Bozen, Italy, 2010.

[15] J. Creswell, Research design: Qualitative, quantitative, and mixed methods approaches: Sage Pubns, 2008.

[16] C. Teddlie and A. Tashakkori, Foundations of mixed methods research: Integrating quantitative and qualitative approaches in the social and behavioral sciences: Sage Publications, Inc, 2009.

[17] S. Kvale, Interviews: An introduction to qualitative research interviewing: Sage Publications, Inc, 1996.

[18] G. Marczyk, D. DeMatteo, and D. Festinger, Essentials of research design and methodology: John Wiley \& Sons, 2005.

[19] M. B. Miles and A. M. Huberman, Qualitative data analysis: A sourcebook of new methods: Sage publications, 1984.

[20] R. Boyatzis, Transforming qualitative information: Thematic analysis and code development: Sage Publications, Inc, 1998. 